\title{
Femtosecond-assisted preparation of donor tissue for Boston type I keratoprosthesis
}

This article was published in the following Dove Press journal:

Clinical Ophthalmology

2I July 20I I

Number of times this article has been viewed

\author{
Majid Moshirfar' \\ Marcus C Neuffer' \\ Krista Kinard' \\ Monette T Lependu' \\ Shameema Sikder ${ }^{2}$ \\ 'John A Moran Eye Center, University \\ of Utah, Salt Lake City, UT, USA; \\ ${ }^{2}$ Wilmer Eye Institute, Johns Hopkins \\ University, Baltimore, MD, USA
}

Correspondence: Marcus C Neuffer John A Moran Eye Center, 65 Mario Capecchi Drive, Salt Lake City, UT84I32, USA

Tel + I 80I 58I 2352

Fax + I 80I 58I 3357

Email mcn04@hotmail.com

\begin{abstract}
We describe a technique for femtosecond laser-assisted preparation of donor tissue for Boston type 1 keratoprosthesis to provide accurate double punching of the donor tissue for optimized alignment in the visual axis. The technique was reproducibly performed in four donor corneas mounted in an artificial anterior chamber. This technique can provide optically centered donor tissue with smooth trephinated edges.
\end{abstract}

Keywords: keratoplasty, femtosecond laser, cornea, laser-trephinated tissue

\section{Introduction}

Indications for keratoprosthesis (Kpro) are refractory corneal blindness with repeated corneal graft failure, and monocular or binocular blindness. ${ }^{1}$ Several different devices exist, but the Boston type 1 Kpro is still the treatment of choice for eyes with adequate tear film and a functional blink. ${ }^{2}$ Surgical preparation of the Boston type 1 Kpro involves using a full thickness corneal donor button, $8.5-9.0 \mathrm{~mm}$ in diameter, with a central trephined $3 \mathrm{~mm}$ hole. Centration of the $3 \mathrm{~mm}$ Kpro pupil on the fovea is integral for image quality. Creating the inner $3 \mathrm{~mm}$ hole first and then centering the outer ring on the inner hole has been hypothesized to improve centration. ${ }^{3}$

Laser has traditionally been used for refractive surgery with the hypothesis that smoother optical surfaces correlate with improved image quality and visual outcomes. ${ }^{4}$ Mechanical blades create resection by shear force, whereas a femtosecond laser generates pulses that create tissue micro photodisruption and cleavage. ${ }^{4}$ Advances in femtosecond laser software and hardware have allowed for use in customized trephination traditional penetrating keratoplasty (PKP), anterior and posterior lamellar keratoplasty, tunnels for intrastromal ring segments, and astigmatic keratotomy. ${ }^{5}$

One study of eight corneoscleral rims created a $2.5 \mathrm{~mm}$ posterior corneal hole and $7.2 \mathrm{~mm}$ diameter stromal pocket, using femtosecond laser, with insertion of an intracorneal Alpha Cor-like Kpro into the stromal pocket. ${ }^{6}$ In a nonrandomized prospective study, femtosecond top hat PKP versus manual top hat PKP had better visual outcomes, less astigmatism, higher endothelial counts, and a trend toward less rejection. ${ }^{7}$ Sarayba et al demonstrated in a comparative study, with mechanical microkeratome and femtosecond laser, that a smoother stromal bed was created with the femtosecond laser. ${ }^{4}$

Many aspects of corneal surgery can now be done on an automated system with the increased flexibility of laser. Tissue separation is more difficult the more edematous the cornea, but can be overcome with higher energy settings. ${ }^{8}$ From the laser studies, 
we propose that a smoother vertical cut for the central $3 \mathrm{~mm}$ and outer $8.5 \mathrm{~mm}$ trephination can be achieved with femtosecond laser. We also propose that maintaining centration of the $3 \mathrm{~mm}$ pupil for the Boston type 1 Kpro will be easier with the femtosecond laser.

\section{Materials and methods}

Four human corneoscleral rims donated for research (Utah Lions Eye Bank, Salt Lake City, UT) were mounted in an artificial anterior chamber (ALTK System ${ }^{\circledR}$, Moria/ Microtech, Doylestown, PA). The anterior chamber was filled with Balanced Saline Solution (BSS) (Alcon, Fort Worth, TX) running from an intravenous line with the bottle height set to 8 feet to maintain an anterior chamber pressure of approximately $40 \mathrm{mmHg}$ measured using a Reichert TonoPen $^{\circledR}$ applanation tonometer (Depew, Erie County, NY). Central corneal thickness was obtained using an ultrasound pachymeter and averaging ten readings.

Two consecutive full-thickness cuts were performed with the femtosecond laser $\left(60 \mathrm{kHz}\right.$ Intralase ${ }^{\mathrm{TM}} \mathrm{FS}$ laser, Abbott Medical Optics, Abbott Park, IL). Each cut used one treatment card. The settings for the first cut included an anterior side cut depth of $1200 \mu \mathrm{m}$, diameter of $3.0 \mathrm{~mm}$, and energy of $2.04 \mathrm{~mJ}$. The side cut parameters were as follows: angle $90^{\circ}$, spot separation 3 , and layer separation 3 . For the second cut, the parameters were kept identical, but the diameter was changed to $8.5 \mathrm{~mm}$. See surgical video for further reference (supplementary video).

The femtosecond laser requires a minimum applanation pressure in order to initiate the laser. For the first cut, this threshold could easily be reached by lowering the laser cone onto the surface of the cornea (Figure 1). Given that

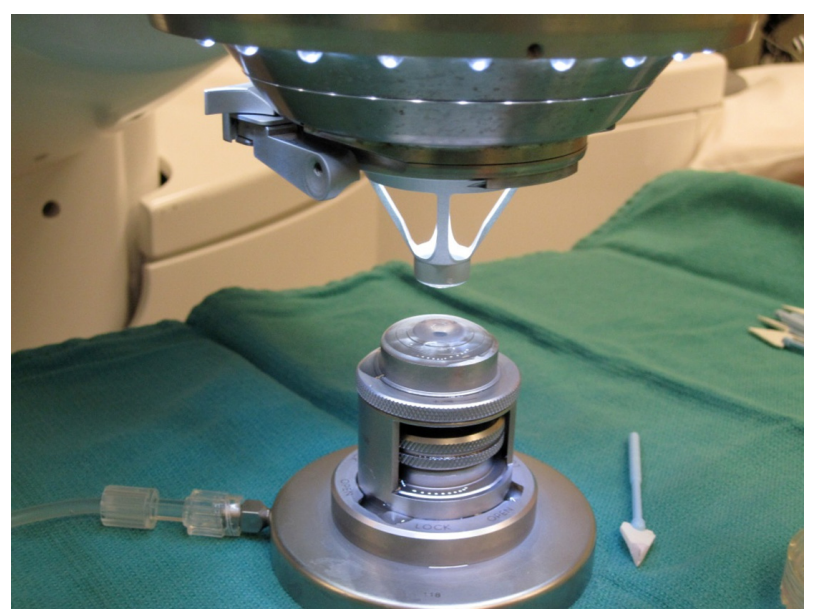

Figure I The setup for applanation of donor cornea with an artificial anterior chamber system and femtosecond laser cone. the laser is not programmed to perform two full-thickness cuts with one treatment card, before the second cut, the laser cone had to be lifted off the surface of the cornea and reapplanated. Since the corneas had full thickness trephination, some fluid did egress through the cut, but the corneas maintained the dome configuration. To prevent distortion of the cornea on second applanation, a light touch was manually applied to the cone to reach threshold applanation pressure. The cone was then gently applied to the cornea to ensure that the meniscus reached the outer limits of applanation.

After the second laser trephination, the laser cone was lifted and the BSS line was occluded to prevent fluid flowing through the cut cornea. Forceps were used to remove the central $3.0 \mathrm{~mm}$ button and then the double-punched donor button from the cornea sclera rim.

Anterior segment optical coherence tomography (AS-OCT) (Zeiss, Jena, Germany) imaging of the donor tissue was obtained by placing the tissue on a flat surface and holding it at the AS-OCT imaging aperture. Separate donor tissue was stored in formalin for light microscopy evaluation with hematoxylin and eosin (H\&E) staining.

\section{Results}

The average age of the four donors was $63.2 \pm 7.0$ years (range: 55-72). The average death to preservation time was $9.1 \pm 2.0$ hours (range: 6.6-10.3). The average storage time was $12.0 \pm 4.7$ days (range: $5-15$ ). The average central corneal thickness was $552.50 \pm 30.60 \mu \mathrm{m}$ (range: 522-595). The average peripheral corneal thickness was $772.0 \pm 118.8 \mu \mathrm{m}$ (range: 650-895).

There was no difficulty in creating the two separate full-thickness cuts using the femtosecond laser, although egress of fluid from the artificial anterior chamber was noted after creation of the smaller $3.0 \mathrm{~mm}$ central trephination, when the cone had to be disengaged and re-engaged.

On gross examination, donor tissue was centrally cut from the corneal sclera rim and had a well centered $3 \mathrm{~mm}$ button (Figure 2). AS-OCT imaging of the donor tissue also demonstrated good centration with smooth vertical cuts of the $3 \mathrm{~mm}$ button and equal amounts of tissue on either side (Figure 3 ). AS-OCT images at $45^{\circ}, 90^{\circ}$, and $135^{\circ}$ also demonstrated tissue with uniform dimensions. Light microscopy with H\&E staining confirmed smooth-cut edges centrally with a minimum area of coagulative type change at the border of trephination (Figure 4). The peripheral edges appeared more irregular than the central edges. 


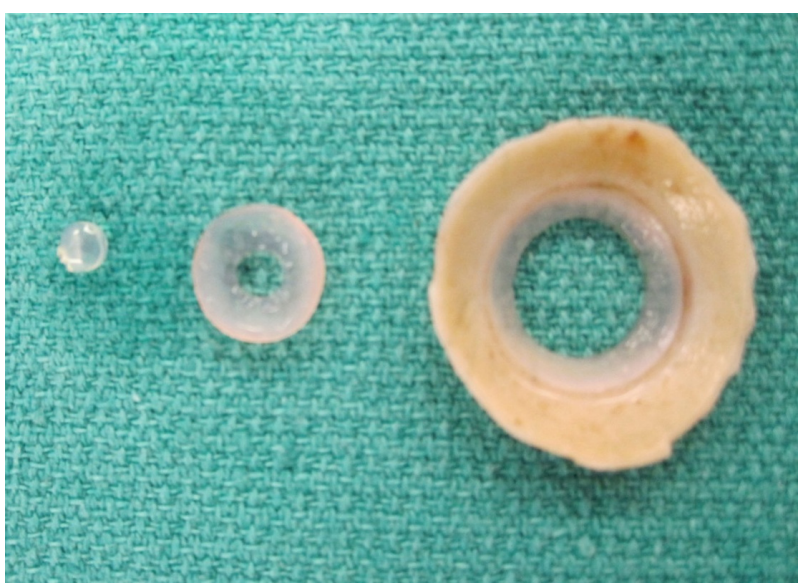

Figure 2 Double trephinated donor cornea for Boston type I keratoprosthesis with central $3 \mathrm{~mm}$ button removed.

\section{Discussion}

The use of a femtosecond laser for facilitating manual steps in surgery has gained popularity in ophthalmology. The appeal of using the femtosecond laser comes from its reliability, reproducibility, precision, and speed. Clinical use of Boston Kpro is longstanding, and great success has been achieved with manual trephination. The purpose of this paper is to demonstrate an additional clinical utility with the femtosecond laser.

The optics of the Boston type 1 Kpro relies on centration of the central optic relative to the macula. In creating an ideal optical system, the optic should be centered within the Kpro. Furthermore, the donor cornea must also be punched centrally. As demonstrated in Figures 2, 3, and 4, the femtosecond laser can produce well-centered cuts with smooth trephinated edges. The use of an artificial anterior chamber does require manual placement of the donor tissue, which can still introduce decentralized error. However, once the donor tissue is mounted, there is a central circle in the artificial anterior chamber which permits facile centration of

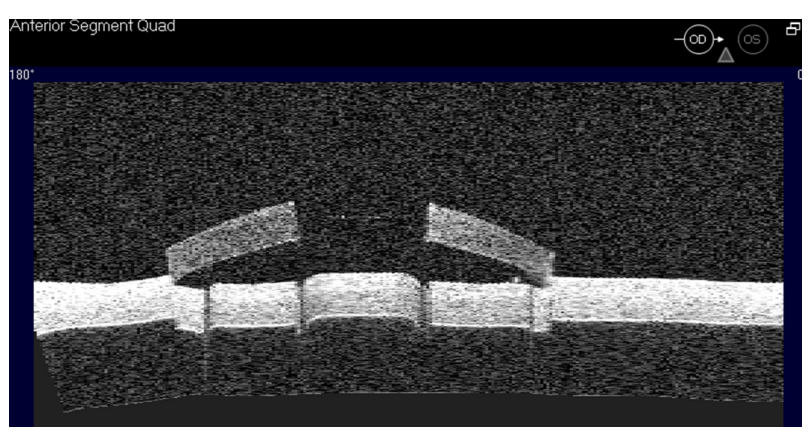

Figure 3 Anterior segment optical coherence tomography image of laser-trephinated donor tissue with well centered vertically cut edges.

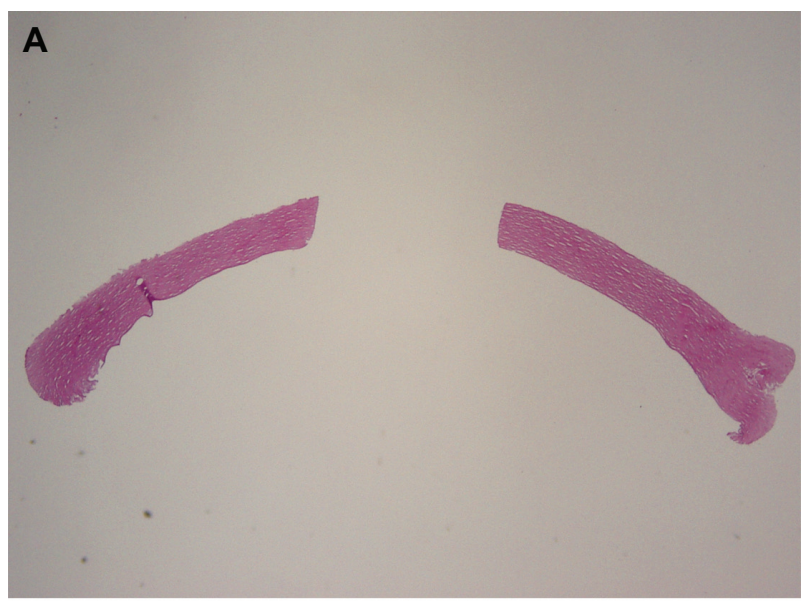

B

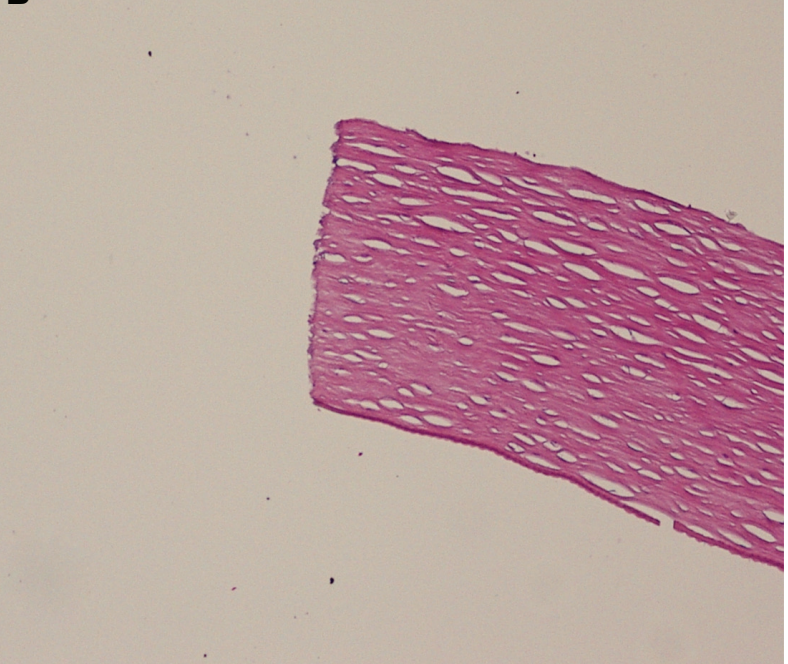

Figure 4 (A) Light microscopy evaluation with hematoxylin and eosin staining at $2 \times$ magnification demonstrating smooth-cut edges with minimum coagulative-type changes of laser-trephinated tissue. (B) Magnification at 10× of laser-trephinated edge.

the laser cone. Even though the laser can optimize centration in the donor cornea, decentralized error can be introduced if the recipient cornea is not centrally trephinated. Thus, surgeons still need to ensure accurate trephination of the recipient cornea.

It is true that the peripheral edges are more irregular than the central edges (Figure 4). This is most likely due to a compromised anterior chamber system after the full-thickness central cut. Currently, the Intralase FS system does have the capacity for double cuts under its Intralase Enabled Keratoplasty settings. However, the software only permits for one full-thickness cut, and the second cut can be set to any depth after sparing the anterior $90 \mu \mathrm{m}$. Perhaps optimization of the software to allow two simultaneous full-thickness cuts will decrease irregularity of the peripheral cut and facilitate use of the laser by eliminating the intermediate step of having to disengage 
and re-engage the applanation cone, and by using only one treatment card for both cuts.

While use of the laser does represent a more expensive method for donor tissue preparation, with regards to optimizing the optical system, it permits advancement. We look forward to the clinical use of the technique described in this manuscript and report of any improvements in visual outcome.

\section{Acknowledgment}

Funding was received from the Research to Prevent Blindness Foundation (New York).

\section{Disclosure}

The authors have no financial interests in any materials or products discussed in the manuscript or any other disclosures to report.

\section{References}

1. Zerbe BL, Belin MW, Ciolino JB; Boston Type 1 Keratoprosthesis Study Group. Results from the multicenter Boston Type 1 Keratoprosthesis Study. Ophthalmol. 2006;113(10):1779.e1-7.

2. Gomaa A, Comyn O, Liu C. Keratoprosthesis in clinical practice a review. Clin Experiment Ophthalmol. 2010;38(2):211-224.

3. Yousuf KM, Moshirfar M. Improved centration of the type 1 Boston keratoprosthesis in donor carrier tissue. Clin Ophthalmol. 2010;4: 931-933.

4. Sarayba MA, Ignacio TS, Binder PS, Tran DB. Comparative study of stromal bed quality by using mechanical, Intralase femtosecond laser 15- and 30-kHz microkeratomes. Cornea. 2007;26(4):446-451.

5. Farid M, Steinert RF. Femtosecond laser-assisted corneal surgery. Curr Opin Ophthalmol. 2010;21(4):288-292.

6. Sarayba MA, Kurtz RM, Nguyen TT, et al. Femtosecond laser-assisted intracorneal keratoprosthesis implantation: a laboratory model. Cornea. 2005;24(8):1010-1014.

7. Bahar I, Kaiserman I, Lange AP, et al. Femtosecond laser versus manual dissection for top hat penetrating keratoplasty. Br J Ophthalmol. 2009; 93(1):73-78.

8. Por YM, Cheng JY, Parthasarathy A, Mehta JS, Tan DT. Outcomes of femtosecond laser-assisted penetrating keratoplasty. Am J Ophthalmol. 2008;145(5):772-774.
Clinical Ophthalmology

\section{Publish your work in this journal}

Clinical Ophthalmology is an international, peer-reviewed journal covering all subspecialties within ophthalmology. Key topics include: Optometry; Visual science; Pharmacology and drug therapy in eye diseases; Basic Sciences; Primary and Secondary eye care; Patient Safety and Quality of Care Improvements. This journal is indexed on

Submit your manuscript here: http://www.dovepress.com/clinical-ophthalmology-journal

\section{Dovepress}

PubMed Central and CAS, and is the official journal of The Society of Clinical Ophthalmology (SCO). The manuscript management system is completely online and includes a very quick and fair peer-review system, which is all easy to use. Visit http://www.dovepress.com/ testimonials.php to read real quotes from published authors. 